\title{
Principal's Facial Expression, Organization Citizenship Behaviour and Performance of Secondary Schools in Nairobi
}

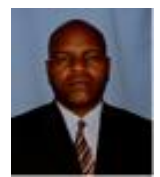

Corresponding Author)

\author{
Godfrey Ngunyi Mute ${ }^{10}$ \\ Peter K'Obonyo ${ }^{2}$ \\ Martine Ogutu ${ }^{3}$ \\ James Njihia $^{4}$
}

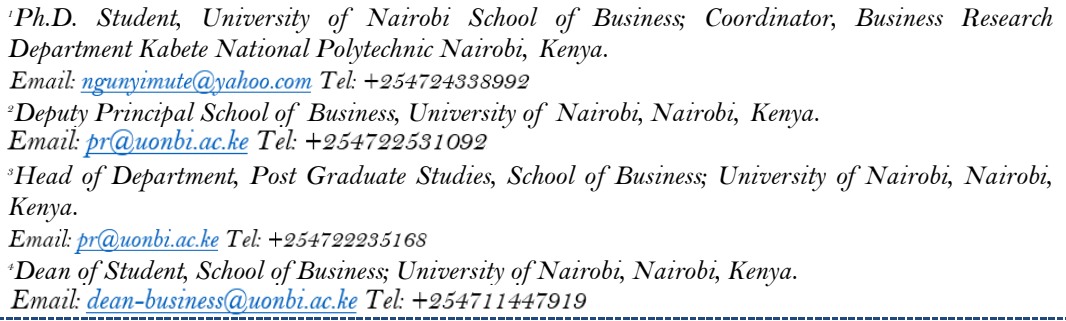

There is no literature in Africa that shows the relationship of leader's facial expression, organization citizenship behavior and performance in learning institution. However each variable is said to affect performance. This study closed the gap by establishing the moderating effect of organization citizenship behavior on the relationship between principal facial expression and secondary school performance in public secondary schools in Nairobi City County. The hypothesis stated that Organization citizenship behavior moderates the relationship between principal's facial expression and performance of secondary schools in Nairobi City County. Research method was a survey method involving positivist's research philosophy, descriptive and cross section research design. A census sampling method was used. 55 secondary schools were considered and 278 teachers were used to respond to the questions. Step by step data analysis method was used. The study finding showed that the moderating effect of organization citizenship behaviour in the relationship between Principal facial expression and Secondary school performance in Nairobi City County was not significant. Conclusion from the study stated that organization citizenship behaviour and Principal's facial expression are independent of each other and affect performance of public secondary schools in Nairobi not in any relationship. It was recommended that each variable should be tested its effect on secondary schools' performance differently.

Keywords: Principal, Facial expression, Organization citizenship Behavior, Performance, Nairobi.

DOI: $10.20448 / 804.5 .1 .134 .140$

Citation | Godfrey Ngunyi Mute; Peter K'Obonyo; Martine Ogutu; James Njihia (2020). Principal's Facial Expression, Organization

Citizenship Behaviour and Performance of Secondary Schools in Nairobi. American Journal of Education and Learning, 5(1): 134-140.

Copyright: This work is licensed under a Creative Commons Attribution 3.0 License

Funding: This study received no specific financial support.

Competing Interests: The authors declare that they have no competing interests.

History: Received: 11 June 2020/ Revised: 13 July 2020/ Accepted: 17 August 2020/ Published: 4 September 2020

Publisher: Online Science Publishing 


\section{Highlights of this paper}

- There is no literature in Africa that shows the relationship of leader's facial expression, organization citizenship behavior and performance in learning institution.

- This study filled the gap by establishing the moderating effect of organization citizenship behavior on the relationship between principal facial expression and secondary school performance in public secondary schools in Nairobi City County.

\section{INTRODUCTION}

Facial Expression or face muscular movement is an important channel of human communication and well, extract emotional features in a person (Zhang, 2011). It is triggered by internal or external event which our body try to control or unable to control. The muscular Facial movement is easily recognized by any person and is known to interrupt thought process.

According to Ekman (1968) facial expression include smiling, making eye contact, opening of the mouth, eye rolling, frowning, appearing bored, scowling, excitement, Interested, or even shock. He noted both Positive and Negative expressions in people conversation. He asserted that, desirable effect, achievement, high excitement is highly associated with positive expression regardless of interpersonal relationship. A negative expression is attached to un pleasant feelings of distress, disgust, shame, and stressful work-related factors. It is important for Professionals like doctors, parents, Human resource managers, and teachers to manager their facial expressions to meet a desirable organization goals.

Senses of feeling of belonging to a place, firm or Organization that make a person to do extra-unpaid duties or take advanced responsibility is known as Organizational Citizenship Behavior (OCB). This behavior does not call for recognition, pay, or any other type of a reward. This behavior both to the employees and managers helps the organization to boost performance and withstands the force of competition from other organization (Organ, 1988). Organization Citizenship Behavior is explained in five face sets; Conscientiousness is commitment and adhering to organization rules and regulation (Law, Wong, \& Chen, 2005).

Civic virtue is the involvement of the employees' behavior getting involved in the extra dairy activities of the organization e.g. games, discipline, clubs, music and Informal organization among others (Law et al., 2005). Altruism is the willingness of the members of an organization having the behavior of helping other members in their task in cases of absenteeism or an equivalent.

Courtesy is that behavior that brings people together, have respect to one another, be close and have good social interaction in area of work. This behavior creates reduction of conflict and emphasis working as a team. Sportsmanship behavior is the tendency or willingness of workers to remain in the organization and tolerate any difficult times of the organization even during the time of depression. For instance, employees going for sometimes with no salaries or accepting adjusting to state that require emergency.

Five identified factors have been selected to improve school performance, namely; past records of student attainment, economic situation of the school stakeholders, type of the school based on the size, public or private and comparison between secondary schools using the main data sets that are available for the school level analysis, (Conwell, 2011).

The people who make education policy give priority to educational research that intend to come up with factors that improve the students' performance in learning institution. Creation of the generated policies are implemented in the learning system to improve students outcome and thus reduce social inequalities. Wanga (2016) asserted that school principal or any education leaders steer the objectives of the schools and therefore hold the core responsibility to communicate this to the teachers who on the other hand have to deliver to the students. He concluded that those leaders hold the keys to affect positive or negative values to the schools. MOEST (2009). 
Showed that in Kenya, there are approximately 4000 public Secondary Schools with approximately 70 Public Schools. This shows that there are more than 4000 School Principals who guide and direct the giving of knowledge to more than one million young Kenyans every 4 years and therefore call for more research on school's leadership.

Communication in form of verbal or nonverbal need to be analyzed and given a critical review in all ways for its purpose, to recreate, promote and persuade the goodwill of the stakeholders of the firm. Anand (2006) found that, for communication to be effective, it is influenced by different variables within or outside the environment in which the communication is taking place.

The variables are between the sender and the receiver, personalities and more so the relationship that exists between the variables. The variation differences imply that difficulties in giving the information or message between two or more people may be generated. The difficulties arises from the perception of the sender towards the receiver, the feeling of the sender or the receiver, the relationship between the sender and the receiver such as staff line relationship, differences in person status or learner-teacher relationship. The study specified on facial expression, Organization Citizenship Behavior and schools' performance.

The study was anchored on trait theory of leadership (Carlyle, 1850) paralanguage non-verbal communication theory (Fernando, 1993) and social exchange theory (George, 1958). Social exchange theory states that, fundamental form of human interaction is created by exchange of material and social resource. Paralanguage / Nonverbal communication theory is the process used to pass message of a person feelings, ideas and thoughts to a second party.

Learning institution were used in the study of this paper where Secondary schools were considered. Education system in Kenya is in five different categories; early child hood education ( ECED), Kenya certificate of primary education (KCPE) to Kenya certificate of secondary education (KCSE), Gumbaro or adult education, Vocation or professional training, higher diploma, Degree, master and $\mathrm{PhD}$ in specialist levels. (UNESCO - UNEVOC. November 2012. Retrieved 12 June (2016).

\section{RESEARCH PROBLEM}

Facial expression communicates both positively and negatively and has great impact in work place. Positive expression has power to give hope and morale to the observers. It indicates enjoyment of ideas and creates innovation and creativity, Matsumoto (2011).

Negative expression demotivates, acts as dissatisfies, gives drawbacks among members of the organization both managers and subordinates. This effect reduces power to work in employees, affect their morals, frustrates them and this problem is projected to other members of family and friends. Overall the organization performance or productivity is negatively affected (Shonubi, 2016). Anand (2006) found that, inability to control personal behavior such as Emotions culturally seen in facial expression and recognize those behavioral emotional cues from others might result to disastrous outcome in the working areas.

Ijaz (2011) found that poor engagement to OCB harm organization or people in the work place. Poor school examination performance, Low enrolment and massive transfers in learning institution are an indication or signs of poor school growth and ineffective.

Visser; Muchimuti (2013); Lawis (2011) in their studies found that facial expression control internal communication and influence a firm's performance. However Ijaz (2011); Marziel (2012) in their study of 131 teachers of both secondary and primary schools showed that the best predictor of organizational citizenship behavior was interactive justice. Common mode of communication used in learning institutions is through face to face between teachers and the students. The mode is applied from Baby class to University education level. 
Effectiveness of communication through this mode is a key role to determine the efficiency in passing message from teachers to students. Study of facial expression in schools is of great importance.

The past literature has not cited any study showing the relationship in School Principal's facial expression, Organization citizenship behavior and Schools' performance in learning institution, which this study is addressing. Besides, the covered literature has indicated that, Facial Expression and Organization Citizenship Behavior separately influence organization productivity or performance.

However, the literature fails to indicate how the variables are linked or work as joint to influence or strengthen Performance. In addition, no literature cited addressing the study of facial expression in African. However, culture differs from one country to another and from a continent to a continent. This study addressed those gaps by responding to the question. What is the role Organization Citizenship Behavior in the relationship between Principal's Facial Expression and Secondary School Performance in Nairobi City County?

\section{RESEARCH OBJECTIVE}

The objective of the study was to establish the moderating effect of Organization Citizenship Behavior in the relationship between Principal Facial Expression and Secondary School Performance Nairobi City County.

\section{LITERATURE REVIEW}

The metacognition patterns of communication affects work behavior decisions, behavior and performance. State of leader facial expression display affects subordinates' facial or emotion display and thus trigger or shows some certainty in their behaviors. Visser (2013) tested leader emotional facial expression on different followers. She found that, leader who displayed positive facial expression to their followers, made them to be creative in performance, whereas leaders who displayed negative facial expression enhanced followers' analytical performance. Her finding showed that when a leader maintained positive facial expression, creative tasks performance improved by $11 \%$ while analytical performance suffered.

However, when the leader displayed negative expression, the creativity levels reduced, while analytical ability increased by $23 \%$. Facial expression is a resource based valuable, interchangeable resource that a firm would use to have advantage of the competitor to improve performance.

Organizational Citizenship Behavior has influenced organization performance, Organ (1988). Podsakoff (2006) studied insurance agency and concluded that $\mathrm{OCB}$ elements of respecting organization rules and regulations, tolerating organization hardship influenced marketing in the company. Further study on paper mills industry, element of altruism was associated with improvement of quality in the product. Civic Virtue and helping behavior improved teamwork in sales. Further study concluded that there are a relationship between OCB, Company profits and growth of the Organization.

Podsakoff, MacKenzie, and Fetter (2000) carried out studies in many companies to investigate the relationship between OCB and overall managerial operations. Eight from the ten studies, found out that OCB had a high score in contribution to managerial evaluation. Altruism or helping behavior was found to have the most effective element of OCB company managerial result. Podsakoff (2006) did another study to examine the application of OCBs during reward allocation and interview. He found that the candidate who accepted to apply the element of altruism during the interview section got high rewarding with a job than those who showed to have no reflection to the use of OCB. 
Independent

Variable

\begin{tabular}{|c|}
\hline Principal Facial \\
Expression \\
-Positive \\
-Negative \\
\hline
\end{tabular}

Dependent

Variable

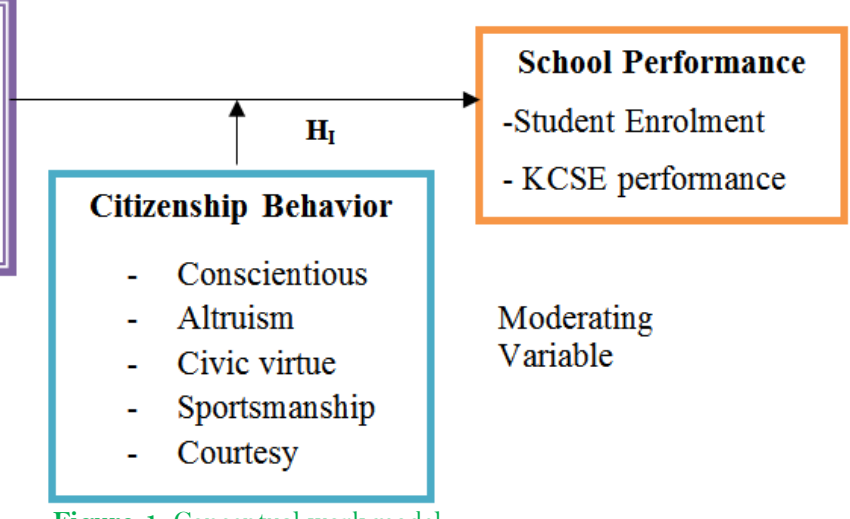

\section{HYPOTHESIS}

$H_{1:}$ Citizenship Behavior moderates the relationship between Principal's Facial Expression and Performance of Secondary Schools in Nairobi City County.

\section{RESEARCH METHODOLOGY}

The study employed positivism philosophy, descriptive and cross-sectional survey research design. The targeted population comprised 55 public County and sub County secondary schools in Nairobi City County obtained from the Teachers Service commission. Proportional to size Probability sampling design was used which produced a sample of 278 out of 916 teachers at a confidence level of $95 \%$ and a margin error of $5 \%$. Simple random technique was used to select the sample from a list of teachers in each school. Primary data was used to measure Principal's facial expression, Organization Citizenship Behavior and student enrolment. Secondary data was used to measure KCSE performance. Cronbach's alpha reliability coefficients for facial expression, Organization Citizenships Behavior and school performance were 0.826, 0.851 and 0.765 respectively and all were reliable. Validity Test covered human resource management competent opinions which ensured that the questionnaire covered all the study variables and the theoretical dimensions emerged as conceptualized (Ogwango, 2012). Besides, 7 randomly selected schools were used for piloting test.

For Normality test, Skewness had a Van index smaller than an absolute value 3 and kurtosis less than 7.0, (Cununghan, Byrne, Bobocel, \& Rupp, 2008). Facial Expression was operationalized as Happiness, Interesting, Surprise, Anger, Fear, Sadness and Disgust. School enrolment was measured by the teachers' perception in student increment in a period of three years. Organization Citizenship Behavior was operationalized as helping behaviors, both directed within or outside of the organization, Reflects the genuine acceptance and adherence to workplace rules regulations and procedures. Recognizing people by sign of greeting, knowing personal names, getting involved in organization activities like clubs or games. A five likert scale ranging from 1'strongly disagree' and 5 'strongly agree' was used to collect the primary data. Data was collected using survey method and analyzed using step by step method. Tables were used to report the data. 


\section{FINDING}

Table-1. Stepwise regression results for the effect of organization citizenship behavior on the relationship between principal's facial expression and secondary school performance.

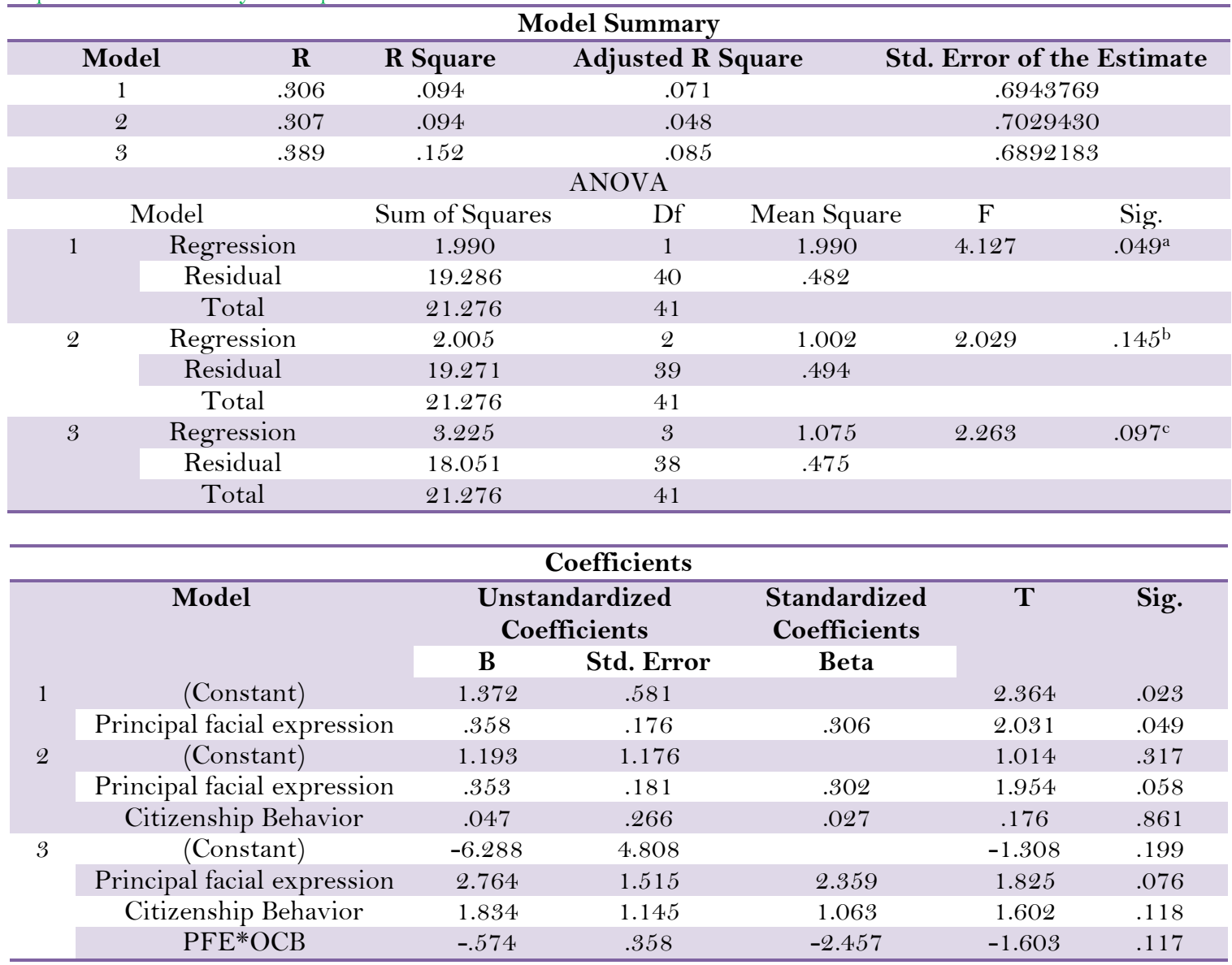

\section{CONCLUSION AND RECOMMENDATION}

Principal's facial expression and organization citizenship are independent variables. In joint effect they don't affect secondary schools' performance in Nairobi City County. The variables do not strengthen each other and therefore the students are not affected by the relationship between their teachers and principal. It was recommended that, direct and separate research between principal facial expression, organization citizenship behavior and secondary school performance should be done respectively. Further research on Facial Expression should be done in different organization set up a part from learning institution.

\section{REFERENCES}

Anand, F. C. (2006). Facial expression and appearance. Journal of Police Human Resource Development, 18(2), 85-100.

Carlyle, J. P. (1850). The trait of leadership personality and success. Journal of Personality and Social Psychology, 12(3), $111-145$.

Conwell, J. C. (2011). Leader-member exchange model of leadership. Journal of Academy of Management Review, 27(1), 195-200.

Cununghan, Z. B., Byrne, D. R., Bobocel, R. K., \& Rupp, D. F. (2008). Moral virtues, fairness heuristics, social entities. Journal of Vocational Behavior, 58(2), 164-209.

Ekman, P. (1968). Constants across cultures in the face and emotion. Journal of Personality and Social Psychology, $17(2)$, 124-129.

Fernando, P. (1993). Textual translation and live translation. Amsterdam: John Benjamins Publishing Company.

George, C. (1958). Social behavior as exchange. American Journal of Sociology, 63(6), 597-606. 
Ijaz, M. F. (2011). Organization Interactive justice. Western Journal of Speech Communicatio, 54(1), 500-544.

Law, S., Wong, C., \& Chen. (2005). Determinanant and consequeences of organizatioal. International Journal of Business and Management Invention, 3(1), 17-23.

Lawis, G. B. (2011). Study of child effective facial expression. Journal of Applied Psychology, 17(3), 538-545.

Marziel, J. (2012). Perception of organization justice as a redicator of OCB Department of management: University of Oluvi Srilanka.

Matsumoto, D. C. (201 1). Reading facial expressions of emotion. American Psychological Association Journal, 25(5), 1-10.

MOEST. (2009). The ministry of education Kenya bereu of statistic: Issue1. Nairobi: Kenya Education Bulletin.

Muchimuti, A. T. (2013). Factor influencing internal organization communication and its role in organization. Journal of Internal organization Influencing Firm Performances, 3(1), 65-89.

Ogwango, I. E. (2012). Influence of head teacher communication strategy on student performances. Management Performance Journal, 2(3), 245- 264.

Organ, D. (1988). Organizational citizenship behaviour: The good soldier syndrome. Lexington MA: Lexington Books.

Podsakoff, P. B. (2006). Individual- and organizational-level consequences of organizational citizenship behaviors: A metaanalysis. Journal of Applied Psychology, 94(1), 122-141.

Podsakoff, P. B., MacKenzie, S. R., \& Fetter, R. E. (2000). Transformational leader behaviors. Journal of the Leadership Quarterly, $1(2), 107-142$.

Shonubi, A. F. (2016). The impact of effective communication on organizational performances. International Journal of Social Services and Humanities, 24(2), 249-295.

Visser, V. K. (2013). Bosses' good moods and bad moods affect team perfomance. Journal of Business Systems Governance $\mathcal{F}^{\circledR}$ Ethics, $5(3), 172-188$.

Wanga, L. R. (2016). Successful school leadership. Journal of educational Administration, 54(3), $270-287$.

Zhang, L. G. (2011). IEEET biometrics transactions on effective computing Compendium. IEEE RFIC Virtual Journal, 2(4), $219-$ 229.

Online Science Publishing is not responsible or answerable for any loss, damage or liability, etc. caused in relation to/arising out of the use of the content. Any queries should be directed to the corresponding author of the article. 